\title{
INDICADORES DE CUIDADOS PARA O CORPO QUE PRO-CRIA: ACÕES DE ENFERMAGEM NO PRE-TRANS E PÓS-PARTO - UMA CONTRIBUIÇÃO PARA A PRÁTICA DE ENFERMAGEM OBSTÉTRICA ${ }^{1}$
}

Nébia Maria Almeida de Figueirêdo ${ }^{2}$ Maria Antonieta Rubio Tyrrel ${ }^{3}$ Vilma de Carvalho ${ }^{4}$ Joséte Luzia Leite ${ }^{5}$

Figueirêdo NMA, Tyrrell MAR, Carvalho V, Leite JL. Indicadores de cuidados para o corpo que pro-cria: ações de enfermagem no pré-trans e pós-parto - uma contribuição para a prática de enfermagem obstétrica. Rev Latino-am Enfermagem 2004 novembrodezembro; 12(6):905-12.

Este estudo é o resultado de dinâmicas entendidas como Cenas de Produção Estética feitas com 28 profissionais de ensino e de serviços de enfermagem para responder a questão: o que se produz sobre o corpo em trabalho de parto quando cuidamos dele no pré, trans e pós - parto? Os objetivos do estudo, que é de natureza qualitativa, foram identificar e discutir as ações nestes momentos em que o corpo da mulher dá origem a uma outra vida. Três categorias surgiram como resultado: 1) O cuidado do corpo em trabalho de parto a (in)devida invasão e a violência velada; 2) O (des)cuidado do corpo que (ex)pulsa outro corpo a invasão e a violência mostrada; 3) O (des)cuidado do corpo vazio: "cansaço e solidão" "a violência do abandono". Estas categorias apontam que existem cuidados para esta clientela como cuidados para a saúde os quais devem evitar a violência sobre o corpo da mulher em processo de parto.

DESCRITORES: cuidados de enfermagem; parto; enfermagem

\section{CARE INDICATORS FOR THE BODY THAT PROCREATES: NURSING ACTIONS BEFORE, DURING AND AFTER DELIVERY - A CONTRIBUTION TO OBSTETRICAL NURSING PRACTICE}

This study results from dynamics seen as Scenes of Esthetical Production, which were accomplished with 28 nursing teaching and service professionals to answer the question: what is generated about the body in labor when we take care of it before, during and after delivery? A qualitative study was realized, which aimed to identify and discuss the actions accomplished at these moments during which the woman's body gives rise to another life. Three categories emerged: 1) The care of the body in labor: the (un)due invasion and concealed violence; 2) the (lack of) care for the body that (ex)pulses another body: the invasion and the expressed violence; 3) the (lack of) care for the empty body: "fatigue and solitude" "the violence of the abandonment". These categories indicated that there are forms of delivering care to this clientele's health, which should avoid violence against the woman's body in labor.

DESCRIPTORS: nursing care; parturition; nursing

INDICADORES DE CUIDADOS PARA EL CUERPO QUE PROCREA:

ACCIONES DE ENFERMERÍA EN EL PRE, TRANS Y POST-PARTO UNA CONTRIBUICIÓN PARA LA PRÁCTICA DEL OFICIO DE ENFERMERO EN OBSTETRICIA

Este estudio es el resultado de dinámicas comprendidas como Escenas de Producción Estética hechas con 28 profesionales de la enseñanza y de servicios de enfermería para responder a la cuestión: ¿Lo qué se produce sobre el cuerpo en trabajo de parto cuando prestamos cuidados antes, durante y tras el parto? Los objetivos del estudio, del tipo cualitativo, fueron identificar y discutir las acciones en estos momentos en que el cuerpo de la mujer da origen a una otra vida. Tres categorías surgieron como resultado: 1. El cuidado del cuerpo en trabajo de parto: la (in)debida invasión y la violencia velada; 2. El (des)cuidado del cuerpo que (ex)pulsa otro cuerpo: la invasión y la violencia mostrada; 3. El (des)cuidado del cuerpo vacío: "cansancio y soledad" "La violencia del abandono". Estas categorías apuntan que existen cuidados a la salud de esta clientela, que deben evitar la violencia sobre el cuerpo de la mujer en proceso del parto.

DESCRIPTORES: atención de enfermería; parto; enfermería

\footnotetext{
${ }^{1}$ Pesquisa financiada pelo Conselho Nacional de Desenvolvimento Científico e Tecnológico-CNPq; ${ }^{2}$ Doutor, Professor Titular da Escola de Enfermagem Alfredo Pinto da Universidade do Rio de Janeiro, Pesquisador do CNPq, e-mail: propgdpg@unirio.br; ${ }^{3}$ Doutor, Professor Titular da Escola de Enfermagem Anna Nery da Universidade Federal do Rio de Janeiro, Pesquisador do CNPq; ${ }^{4}$ Doutor, Professor Titular Emérito da Universidade Federal do Rio de Janeiro, Pesquisador do CNPq, ${ }^{5}$ Doutor, Professor Titular Emérito da Universidade do Rio de Janeiro, Professor Visitante da Escola de Enfermagem Anna Nery da Universidade Federal do Rio de Janeiro, Pesquisador do CNPq
} 
INTRODUÇÃO-CONSIDERAÇÕES PASSAGEIRAS

Toda vez que escrevemos temas sobre cuidado em enfermagem, temos nos questionado e tido o cuidado de averiguar que novidade poderemos estar trazendo para os nossos leitores mais atentos. Uma posição temos tido, manter a essência do tema fundamentado numa prática para que a teoria encontre eco e consistência.

Neste estudo, uma de nós é especialista na Área de Obstetrícia e as outras três envolvem-se mais com a prática e a teorização do cuidado na enfermagem assistencial.

Pensar na mulher em trabalho de parto, onde o seu corpo tem sido o espaço de "violência velada", na área da saúde, principalmente quando a enfermagem encontra-se no mesmo espaço de atender a esta mulher, é no mínimo estranho para nós pensar uma prática violenta.

A idéia de teorizar sobre 0 tema surgiu no 1 은

Encontro da Associação Brasileira de Enfermagem em Obstetrícia, ABENFO, em 1999 no Rio de Janeiro, UERJ, uma vez que nossa premissa é sempre ofertar cuidados confortantes que protejam nossos clientes de qualquer dano físico ou emocional, o que é oposto da violência - entendida com ação que cria uma brecha entre o que é, o que não é enfermagem de conforto, de qualidade, e arte de cuidar.

Uma violência entendida como um poder sobre o corpo do outro, que faz mal: uma violência que desloca a arte de cuidar e que nos impede de olhar de modo sensivel para o sujeito do cuidado.

Uma ação violenta sobre alguém retira toda a possibilidade de pensar numa ação de cuidar. Na verdade um olhar que considera a violência é entendido como "um olhar que desarruma, permanentemente as significações produzidas pelo simbólico e exige insistentemente a produção de novas interpretações e de novos olhares" (sobre as mulheres em trabalho de parto).

No entanto, não é este olhar que faz parte de nossa prática, que está enrijecida por uma violência silenciosa, que está nas salas onde as mulheres são atendidas e não cuidadas, onde a violência não poderia veicular nas ações de saúde, por que ela é o contrário ela é doença.

A nossa estranheza está em perceber que a prática de cuidar tem perdido sua função, produzindo implosão de certezas (nossas) sobre o cuidado, provocando colapso de uma trajetória da "função de cuidar" e negando a própria possibilidade de que a enfermagem aconteça "com cuidado" e não como se ela "fosse obra do

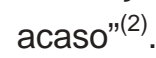

A violência sobre o corpo da mulher em trabalho de parto tem sido um contexto motivador de desconforto, que aparece permanentemente justificada nas condições físico-emocionais dos cuidadores, nas condições de trabalho, no sistema de saúde em franca desarrumação. Na verdade, é como se tudo estivesse sendo violentado.

Conseqüentemente, essas afirmativas reproduzem-se nos discursos e nas áreas de ação dos profissionais de saúde, fazendo com que não se cuide do jeito que achamos que deve ser.

Se assim pensamos é possível acreditar que estamos lidando não com a "morte real", mas com uma "morte subjetiva" que se instala e se instaura veladamente através da violência que os corpos (o de equipe de saúdeenfermagem) causam nos corpos de seus clientes, no caso específico, das mulheres em trabalho de parto. Isto parece estar de acordo com o trabalho no hospital, que é um ofício e tem uma natureza, que faz com que as pessoas tenham medo de adoecer e temer sua própria morte, onde a exigência de um saber e de uma técnica parece ser o refúgio do medo e da precariedade assim, os profissionais se sentem: "o impedido de sentir e expressar este sofrimento na ocorrência de doenças (ou não, no caso do parto), com a interdição da sua manifestação pública (poderia ser o parto em casa) que obriga aos doentes sofrerem às escondidas e aos que assistem a um discreto e sofrido trabalho"(3).

Com estas considerações, passageiras, nos perguntamos: o que se produz sobre o corpo em trabalho de parto quando cuidamos dele no pré, trans e pós-parto? Estas questões que emergem do objeto de pesquisa, entendido como: indicadores de cuidados de enfermagem a mulheres em trabalho de parto, pode ser resolvida com os seguintes objetivos: identificar e discutir as ações de enfermagem quando cuidam de mulheres durante o prétrans e pós-parto.

A justificativa do estudo está na busca de indicadores de qualidade (conforto) para o cuidado de enfermagem nesta área. Além do mais, criar na enfermagem um modo de cuidar, utilizando indicadores, por que esta não tem sido a sua prática.

$\mathrm{Na}$ verdade, quando usamos indicadores, 
utilizamos, sempre os de morbi e mortalidade, todos voltados para doença em nome da saúde.

Também não estamos procurando em que espaços de cuidar estes indicadores podem estar e que precisam ser identificados para que possamos ir ajustandoos a uma prática que não está bem e que precisa urgentemente ser revista, revisada, redirecionada.

\section{METODOLOGIA - A BUSCA DE INDICADORES}

A produção dos dados, após trabalhar as informações (visuais e cognitivas) sustenta-se na abordagem qualitativa a partir de estratégia sensível de brincar como uma forma de permitir, pensar, teorizar e agir, para não só buscar as bases concretas precisas, dedutivas apenas. Numa dinâmica de criar brincando é possível pensar na articulação do que é aceito como ciência (dedução) com o que é impreciso, ocasional, emocional, sensível. Brincar como criança ou como adulto e talvez seja esta a forma "de fazer com que a liberdade flua em busca do eu" que de um modo mais direto se torna mais difícil de encontrá-lo. É no brincar que a pessoa manifesta sua criatividade e nela coloca coisas guardadas que às vezes não lembra ou não considera importante: "no brincar é possível a comunicação, que não é a direta”(4).

Esta afirmativa é do entendimento de que a pesquisa qualitativa, suporta brincar e criar, e na enfermagem, permite que estejamos tão próximos possível dos sujeitos-objetos, os quais estão em constante movimento de interação-integração como personagens do estudo com os pesquisadores, quando estes buscam respostas para suas questões.

Neste estudo, os participantes são 28 profissionais de enfermagem de ensino e de serviço, (11 docentes e 14 enfermeiras e 3 enfermeiros) que aprendem a teorizar sobre a prática de cuidar em obstetrícia.

Eles pertencem a diversos serviços e cursos de pós-graduação em enfermagem e estão com mais de cinco anos de ação na área e têm entre 25 a 45 anos de idade.

A construção dos dados indicadores, foi realizada durante uma Oficina de Criação no 1ํ Encontro da ABENFO denominada de: Oficinas de Produção sobre a Enfermagem. O espaço da atividade brincar/imaginar que chamamos de Cenas de Produção Estética onde os personagens do estudo modelaram o cuidado com o corpo em trabalho de parto, respondendo a questão desta pesquisa. A opção pela estratégia, também entendida como dinâmica de expressão, é uma opção das autoras que já vem colhendo informações nesta modalidade há mais de 8 anos. As cenas de Produção Estética são entendidas como um espaço alternativo metodológico, onde a maioria dos objetos de pesquisa concentram-se em corpos sadios ou corpos doentes que são cuidados pela enfermagem. Corpos que não podem ser considerados fora do contexto das nossas pesquisas. Neste espaço expressivo é que se cria um papel para que o personagem possa atuar numa sociedade hostil, doente sem esperança (composta de clientes e cuidadores que perambulam nos serviços de saúde). É neste espaço de expressão - o teatro que "alguém é preparado para a vida toda", onde se trabalha inquietações "através da imaginação criadora, inquieta e livre"(5). Estas cenas de produção encontraram perfeita aderência ao teatro de STANISLASVISKI quando diz que é nele que se produz representações sobre sujeitos-objetos. Nelas os temas são pensados, apresentados, representados, podendo ser "uma simulação, uma cena artificial, um teatro místico do sistemismo, que pode resultar em bifurcações, remanejamentos estruturais e remanejamentos de

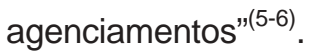

A dinâmica foi desenvolvida após explicação dos objetivos do estudo e da autorização dos participantes para utilização das Imagens Visuais e Cognotivas (foto, modelagem e as falas). Informamos que elas deveriam modelar o cuidado com o corpo em trabalho de parto, tentando responder a questão do estudo. Distribuímos massa de modelar de várias cores e papel ou papéis, cola, figuras. Em seguida, da criação-representação de cada uma (a imagem visual) solicitamos que nos explicassem o porque das imagens construídas, fortalecendo com as falas (imagens cognitivas) o que elas pensavam sobre: 0 que se reproduz sobre o corpo em trabalho de parto, quando cuidam dele no pré-trans e pós-parto. As falas foram gravadas e registradas pelos pesquisadores, (uma vez que o gravador, num dos momentos não funcionou). Fotografamos as pessoas e o material produzido, quando faziam as modelagens ou colagens. Lei Federal 7.300 art. 50 de 27 março de 1985. (sobre a imagem, fotos..)

Destacamos que este tipo de atividade tem interessado a todos, quanto quem aprende quanto quem ensina enfermagem, e destas cenas muitos dados têm sido produzidos. 
TRABALHANDO O MATERIAL PRODUZIDO - OS DADOS

De posse do material produzido nas falas e nas imagens visuais, destacamos o que nos era familiar ou que não era. Assim identificamos os indicadores como:

- Primeiro - O cuidado com o corpo em trabalho de parto: a (in)devida invasão do corpo e a violência velada; - Segundo - O (des)cuidado com o corpo em trabalho de parto: O corpo que (ex)pulsa outro corpo a invasão e a violência mostrada;

- Terceiro - O (des)cuidado com o corpo vazio: "cansaço, a solidão" a violência do abandono.

\section{OS RESULTADOS - ANÁLISE E DISCUSSÃO DOS INDICADORES}

- O primeiro indicador

O cuidado com o corpo em trabalho de parto: A (in)devida invasão do Corpo e a Violência Velada

Este indicador trata dos cuidados realizados no pré-parto, onde são indevidos e invasivos, mas necessários porque tratam de exames de toque, tricotomia, lavagem intestinal. A mulher chega ao hospital com o seu "corpo cheio"; com o corpo em "procriação" e se instala num primeiro território, que ela não conhece, como também não conhece seus habitantes - os exercentes da enfermagem.

Além do mais, é um momento exclusivo de um gênero, onde a violência é constante sob todos os aspectos.

No caso específico da saúde, a violência é velada em nome de uma técnica, em nome de um tratamento, como se a mulher estivesse doente.

É também neste espaço, a sala de pré-parto que as diferenças hierárquicas se aguçam, pois os profissionais de saúde no caso particular da enfermagem, detém o poder sobre o corpo da mulher em trabalho de parto, indicando o que fazer ou até mesmo invadindo-o sem a sua permissão.

Uma enfermeira expressou-se como se sala de pré parto fosse a "clausura da cliente": A mulher quando chega na maternidade perde a identidade e a proteção, mas em nome do preparo do corpo para o trabalho de parto invadimos o seu corpo para tricotomia, lavagem intestinal no momento em que ela começa a sentir a dor. É um cuidado desconfortante e que invade a privacidade mesmo que a gente pense numa clausura para ele que é o pré-parto ENF1.

"A autoridade é sempre exercida sobre os menos fortes ou que não tem autoridade, entretanto, não implica necessariamente em violência. No entanto, mesmo a violência pode ocorrer num clima de extrema amabilidade e afeto"(7). Este mesmo autor chama a atenção para a vitima e vitimização que está nas relações de poder, onde uma é da ordem de macro poder e a outra é do micro poder ${ }^{(7)}$.

Outra fala que se expressa como "proteção materna": ... Não há proteção. Às vezes penso numa cesta para ela ficar. Na sala de pré parto tentamos apoios, cuidar mesmo que a lavagem intestinal e a tricotomia não sejam o melhor. Mas a enfermagem tenta dar conforto e tranqüilidade na sala de parto. Isto eu sei que fazemos, depois é que tudo se desarruma, lá na sala de parto Enf 2.

Neste caso, observamos que as mulheres são vítimas pela violência que a atenção à saúde produz em seus corpos.

Mesmo que a enfermagem afirme o tempo todo que na sala de pré-parto ela tenta colocar a cliente o mais confortável que pode, não é possível esquecer que as "relações humanas apresentam um certo grau de tensão nem sempre negativo"(7).

Ao contrário das relações violentas que são extremamente tensas e que invariavelmente caminham para uma negatividade, como é o caso dos cuidados necessários com a cliente no pré-parto, pois eles são desconfortantes e dolorosos muitas vezes.

Mesmo assim, quando a violência é necessária é algo que não agrada as enfermeiras, que de fato, estão preocupadas com o conforto de suas clientes.

As enfermeiras dizem que a ...sala de pré-parto éo cartão de visita da maternidade. É ali que as mulheres podem se sentir bem ou se sentir mal, por que são os primeiros contatos que permanecem, as primeiras relações são as que marcam Enf 3. "É um espaço onde se cria vínculos sociais imprescindíveis à existência humana, que podem ser positivas ou negativas"(7).

Acreditam as enfermeiras que trabalham em obstetrícia que a enfermagem apresenta e reforça sua prática quando estão cuidando das mulheres em trabalho de parto. O espaço social da enfermagem, a sala de préparto - que ela pode obter aprovação social, "absolutamente necessário ao ser humano como membro de um grupo social, pois é seu sentimento de pertinência que está em jogo"(7). 
Muitos de nós tem pensando nesta violência entendida como cuidado desconfortante e como invasão de privacidade. Um cuidado que impede os sujeitos que estão sendo cuidados de se sentirem sujeitos de seus próprios corpos.

É também na sala de pré-parto, que as enfermeiras dizem perceber que as mulheres, naquele momento, se tornam impotentes e a mercê delas que têm o poder instituído pela lei do Exercício Profissional para invadir aquele corpo que não lhe é íntimo, que elas não conhecem. A legitimidade contida nos procedimentos de cuidar, afirmase como rotina cotidiana e a violência é uma realidade por que é uma necessidade instituída - são técnicas, procedimentos/comunicação que desvelam condutas denotadoras de poder sobre o corpo da parturiente.

Assim, a violência passa a fazer parte das práticas de cuidar que penetram nos corpos das mulheres as quais diante da impotência em reagir, reforçam a reação da dor do corpo que se prepara para expulsar uma vida nove meses guardada.

As informações contidas neste indicador são representações vividas, numa prática que as enfermeiras têm do corpo em trabalho de parto que está inteira e em ação no cuidado em obstetrícia. São representações, que não se confundem com vivência de cuidar. Muitas vezes "são imagens que as vivências assumem no nível simbólico e de cuja elaboração o inconsciente, individual e coletivo, participa ativamente"(7).

A base material deste indicador são as imagens visuais e as falas das enfermeiras que guardam uma violência velada, de representações diferentes onde cada uma das mulheres tem um modo de produzir diferentes imagens para as enfermeiras ou sua equipe, que conhecem à distância os sinais do trabalho de parto, mas sequer imaginam saber quem é aquela mulher grávida, que é igual as outras em sua aparência corporal-física.

Há também uma violência velada que não é provocada pelas práticas das enfermeiras, mas pela fala dos profissionais da medicina que não as respeitam e trazem para o ambiente do cuidado, reproduções que estão na história das famílias onde o homem sempre é o detentor do poder.

As enfermeiras citaram, com freqüência, nas suas falas, que são comuns nas abordagens de seus colegas de trabalho as seguintes expressões: ...na hora de fazer o filho você geme de prazer... e ...elas ficam submetidas pelo mêdo... Enf 4. É uma violência que oprime e cala. Aqui todos ficam subalternos a um único poder, destacando-se que na sala de pré-parto as enfermeiras dizem ser o espaço da tranqüilidade (velada, diríamos nós), onde se cuida para o momento seguinte. O olhar é sempre para o útero, onde esquecemos que tem um marido grávido, uma família grávida e que os profissionais de saúde também estão grávidos. O trabalho todo é para o nascimento de um bebêútero que não é personificado. É neste momento que a enfermagem diz que é preciso dar atenção a mulher e "não só o atender ao útero... pensando em seu aparelho reprodutor, mas na mulher inteira com suas características pessoais e sentimentos próprios"(8).

É neste momento, ainda, que as enfermeiras dizem manter o equilíbrio através do conforto, no entendimento, de que é uma mulher que está ali - com emoções e hormônios a flor da pele. Questões para um atendimento que dificulta a ação humanizada "tempo curto da consulta; grande volume de atendimento; rodízio de plantões impedindo o vínculo entre o profissional e a mulher; a baixa remuneração e as condições de trabalho" ${ }^{\text {"(8) }}$. Assim, as enfermeiras encaminham para a sala de parto, uma mulher aparentemente tranqüila como afirmam. Em seguida mostraremos o segundo indicador que enriquece e dá consistência a este.

- O segundo indicador

O (des)cuidado com o Corpo em trabalho de Parto: o corpo que (ex)pulsa outro corpo a invasão... Violência Mostrada

...A natureza faz tudo tão direitinho. Tudo tem ordem, tudo é guardado dentro do corpo com muito cuidado. Tempo para criar, para que as células cresçam, o corpo do neném comece a tomar forma. No dia de nascer é sofrimento, muito diferente do dia em que o bebê foi feito. A dor acompanha a mulher e nós pioramos com nossas técnicas, nossa invasão. Às vezes, tudo é tão mecânico... No preparo, tentamos tranqüiliza-la mas com a tricotomia e a lavagem. Mas a pressa na sala de parto estraga tudo e vai contra a natureza do corpo. Deviam esperar Enf. 5 e 6.

Neste momento, o corpo da mulher em trabalho de parto, torna-se cada vez mais contido e traído por uma situação que ele não quer, mais não domina. A violência sobre seu corpo é mostrada em toda sua "bruteza" quando é colocada na mesa de parto, contido e exposto onde a pressa é a ordem constante mostrada nos movimentos e nas falas: ...precisa nascer logo, faça força, monte em cima dela e empurre a criança; coloque ocitocina para apressar o parto...; precisamos acabar logo com isso Enf. 7. Essas 
falas na sala de parto indicam que as enfermeiras consideram um (des)cuidado para o corpo que está em vias de expulsar um outro corpo.

... o parto é uma violência no corpo da mulher, principalmente depois que inventaram hospital-maternidade. Eu tento passar conforto no pré-parto, é onde a enfermagem está mais presente; só com ela. Na sala de parto a pressa impera..., tudo é feito correndo e o parto acontece fora do tempo da natureza do corpo. Enf. 8.

É a violência mostrada num corpo que durante nove meses conviveu com tantas mudanças para adaptarse a inúmeras reações que o estado de gravidez exige físicas e emocionais.

Este corpo agora (re)velado é um corpo traído, por que ninguém the explicou e nem pediu autorização para expô-lo, mostrar sua internalidade, seu interior, expondo sua intimidade, sua sexualidade.

Agora, é a imagem e a realidade que se confundem. Imagem entendida como aquelas que se referem a símbolos e criações mentais em oposição à realidade da experiência física ${ }^{(9)}$.

No entanto, são as enfermeiras que dizem: ...na sala de parto tudo fica confuso, desarrumado, muita pressa e a mulher em trabalho de parto está atenta a esta nova experiência. Enf. 9.

A sala de parto é o segundo ambiente que ela se encontra, na maioria das vezes as pessoas que cuidam dela são outras - outro território, outros sujeitos do cuidado.

Seu corpo viveu esta experiência exteriormente num ambiente estranho que lhes provoca novas impressões sobre o cuidado que recebe e às vezes essas experiências são fortes o suficiente para afetar os seus sentidos. Outra enfermeira diz que

...A mulher sente dor, poucas respeitam esse momento. $O$ excesso de toque é uma violência em nome de uma criança e em nome de uma ciência que não é confortante. O parto no hospital é apressado. Enf. 10.

Neste momento, nem sempre, os profissionais estão preocupados com os sentimentos ou as emoções das mulheres que muitas vezes "gritam de dor". Apesar do avanço da tecnologia, ter filho no hospital é uma prática normal, mas bastante utilizada, enquanto que o parto é algo natural e deveria ser fora dele, salvo em situações de patologia.

Quem de nós se preocupa com o medo do parto que muitas mulheres têm? Do poder dos profissionais da dor? Do medo da morte do bebê ou de um bebê anormal?
De vivências anteriores, de sua própria história de vida, de sua cultura e até da educação que recebeu em sua família como "o confronto com o limite da própria vida. Ter o filho é ter que dar de si, dar parte da própria vida, o que significa lidar com a própria morte"(8).

O corpo traído também é o corpo contido, amarrado à mesa de parto pelas pernas, onde todos a sua volta tem pressa e por isso se movimentam em torno dele com coisas e expressões que ele não entende. É um corpo totalmente controlado, tanto no seu aspecto exterior, quanto na sua estrutura interior.

A imagem corporal construída durante nove meses se desfaz no momento do parto, não fica mais como era e nem permanecerá cheio e isto pode perturbar a mulher. As enfermeiras falam de uma harmonia que se perde neste momento e que elas precisam cuidar de um cuidado que apresenta-se como "descuidado" como ajudar a mulher a aceitar este novo momento onde o corpo se redesenha diferente e que mexe com o espírito e com os sonhos da mulher.

As enfermeiras dizem que é um momento de alegria da descoberta de um corpo que já não é mais, agora é feio, é mole, com estrias, aumentando, com manchas faciais. São imagens do corpo que se esvazia e encontra eco na imagem corporal desempenha duas funções importantes na vida do adulto. "Sente como modelo de execução para a atividade motora consciente, que é dirigido, ensaiado subconscientemente é uma imagem corporal inadequada. No entanto, a função da imagem corporal que serve para localizar sensações, o que pode facilitar ou impedir um determinado tipo de

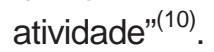

Esse segundo indicador, tem um apelo que as enfermeiras ainda buscam descobrir na forma de cuidados e que serve para qualquer mulher em trabalho de parto que é o cuidado com a auto-imagem, com o medo, com a dor, com a ansiedade e tensão, pelo desconhecimento do corpo e de seus hormônios durante as contrações.

As enfermeiras sabem que o carinho e o bom trato durante o trabalho de parto é a terapêutica certa e que muito pode ajudar a mulher. E esse cuidado começa no primeiro mês de gestação e termina na sala de parto quando o bebê nasce.

Uma das dificuldades registradas pelas enfermeiras e de que na maioria das vezes ninguém sabe as causas da origem da dor para poder combate-la o que pode estar no entendimento de muitos é o de que a mulher grávida está doente. 
É importante para ela estar junto de um profissional que confie. Sem ele, uma pessoa estranha pode provocar a sensação de desproteção de mulher grávida, tornando-a "angustiada e insegura mais do que nunca num dos momentos de maior solidão de sua vida"(8).

Em outras falas as enfermeiras repetem o que já foi dito:

...A mulher sente dor, poucas respeitam esse momento. $O$ excesso de toque é uma violência em nome de uma criança e em nome de uma ciência que não é confortante. O parto no hospital é apressado. Enf. 10.

...Esses são momentos de felicidade. Ela chega com dor mas tem uma face alegre. Às vezes o sangue a apavora e ninguém Ihe explica muito bem...A posição na sala de parto também faz com que ela se acostume com uma enfermagem, lá dentro tudo muda, tudo é pressa. Enf. 11.

\section{- O terceiro indicador}

O (des)cuidado com o Corpo Vazio: o cansaço, a solidão e a Violência do Abandono

Este é o momento que o corpo se esvazia. O bebê nasce e todas as atenções se voltam para ele. A enfermagem o protege levando-o para os primeiros cuidados enquanto a mulher cansada fica só. Neste momento, ela deixa de ser a atenção principal, diz as enfermeiras do estudo. Ao abandoná-la, se quer imaginamos como a mulher vivencia essa experiência e como simboliza esta nova fase de sua vida quando deu origem a outra vida.

...O bebê nasce e fica tudo desarrumado...Carregam o seu bebê e ela fica só e com dor... Acho isto muito violento, precisamos fazer alguma coisa. Enf. 11.

... O corpo agora é um grande vazio..., mas a pressa continua, a placenta é quase que arrancada... Os restos de seu corpo que mantiveram a vida são jogados... as pernas delas tremem de cansaço... Enf. 12 e 13.

Ao parir, o corpo entra em depressão física e emocional, como as enfermeiras percebem no seu cotidiano da sala de partos.

A depressão é normal desde que seja passageira: "uma pessoa desanimada recuperará sua fé e esperança quando a situação mudar"(9).

Neste caso, as enfermeiras sabem que uma mulher num médio ou longo trabalho de parto merece cuidados de atenção direta e muitas vezes ela expressa o desejo de estar com alguém próximo que lhe segure a mão ou que fique ao lado, ou então, que deseja ficar só, quieta. Em outros momentos, ela pode ficar irritada ou impaciente.

A sala de parto é um espaço de movimento intenso, que aumenta com a chegada do bebê e diminui logo depois com a saída do neném para o berçário.

Outra fala:

... O bebê está num lugar que ela não sabe aonde é. Os profissionais continuam sobre seu corpo, tirando a placenta, costurando... Agora, ela está só, o corpo está vazio... todas as atenções estão voltadas para o bebê...é a violência da solidão... Enf. 14 e 15.

A mulher abandonada, a espera do deslocamento da placenta indica que há um descuido de um corpo agora vazio que "parece" não interessar mais a ninguém. Às vezes, para algumas mulheres grávidas, "pode ser doloroso ter de se separar do filho que estava na barriga, e para outros pode ser um alívio colocá-lo para fora”(8).

...Depois que levaram seu filho elas viram uma poça de sangue e só saiu a placenta. Todo o cuidado que tivemos no préparto é destruído na sala de parto Enf. 16.

As enfermeiras afirmam que esta situação de abandono, também é uma violência contra a mulher, que reproduzimos em nossas práticas que envolvem a estética, o novo, a novidade. Ao invés de abandoná-la, a enfermagem deveria prepará-la para dormir, para recuperar energias perdidas, para limpá-la, tornando-a confortada no físico e na alma.

Uma outra questão deve ser considerada quando se pensa em cuidado, que é a brusca queda de hormônios e as cólicas para contração do útero, acompanhados com o medo de voltar para casa com um primeiro ou mais um filho para criar; voltar ao que era; enquanto o corpo e despertar novamente desejo. Todas essas preocupações podem desencadear solidão.

A enfermagem deveria, diz as enfermeiras, prolongar o cuidado para que a parturiente não se sinta abandonada; que não sofra a tão comum auto-depressão e a auto-censura; para que possa se sentir segura para cuidar da família.

Com essas falas apresentamos os resultados dos indicadores de cuidados.

\section{CONSIDERAÇÕES DE PASSAGENS}

Identificamos que os indicadores encontrados podem contribuir para a compreensão de uma prática em 
obstetrícia que considere o corpo que pró-cria quando chega a maternidade e apresenta-se aflito, com dor que é tranqüilizado e apoiado pela enfermagem no pré-parto; mas que se desarruma e se angustia na sala de parto pela pressa dos profissionais; que deprime após e nascimento do bebê pelo abandono.

$\mathrm{Na}$ verdade, o (des)cuidado de enfermagem arruma, desarruma e abandona o corpo do cuidado, indicando que há uma complexidade nos momentos de parir - indicadores de organização, desorganização e reorganização para o cuidado de enfermagem em obstetrícia, que poderá vislumbrar uma enfermagem movimento, que acompanha os ritmos do próprio corpo que (ex)pulsa uma outra vida e que os abandonos podem ser considerados saídas estratégicas, nunca um abandono ou violência. No entanto, a enfermagem obstétrica precisa aprofundar este objeto de estudo e teorizar mais sobre o que encontramos nestes indicadores Vimos que é uma prática assistencial/de cuidado "que tem provocado uma angústia entre as mulheres, para quem o parto é simbolizado como um evento de riscos e dor fisica. Além do temor inerente ao parto, a mulher sente medo de quem a atenderá uma vez que suas experiências próprias ou de outras mulheres de seu convivio estão repletas de atendimento impessoal e distante, por parte dos profissionais" ${ }^{\text {(11). }}$.

\section{REFERÊNCIAS BIBLIOGRÁFICAS}

1. Borges SN. Metamorfoses do corpo: uma pedagogia Freudiana. Rio de Janeiro (RJ): FIOCRUZ; 1996.

2. Maluf V. Cultura do Mosaico: uma introdução à Teoria das estranhezas. Niterói (RJ): Sol Nascente; 1997.

3. Pitta A. Hospital dor e morte como ofício. $2^{\underline{a}}$ ed. São Paulo (SP): Hucitec; 1991.

4. Winnicott DW. O brincar e a realidade. Rio de Janeiro (RJ): Imago; 1975 (coleção Psicologia Psicoanalítica).

5. Stanilasviski C. A criação de um papel. 5aㅡ ed. Rio de Janeiro (RJ): Civilização Brasileira; 1995.

6. Guattari F. Cadernos de Subjetividade do Núcleo de Estudos e Pesquisas da Subjetividade da Pós-Graduação da PUC. $2^{a}$ ed. São Paulo (SP): PUC; 1996.

7. Saffioti H, Almeida SS. Violência de gênero: poder e impotência. São Paulo (SP): Summus; 1993.

8. Ávila AA. Socorro Doutor! Atrás da barriga tem gente! São Paulo (SP): Atheneu; 1998.

9. Lowen A. O corpo traído. São Paulo (SP): Summus; 1979. 10. Lowen A. O corpo em depressão: as bases biológicas da fé e da realidade. 4a ed. São Paulo (SP): Summus; 1983.

11. Caron OAF, Silva IA. Parturiente e equipe obsterica:a dificil arte de comunicar. Rev Latino-am Enfermagem 2002 julhoagosto; 10(4):485-92. 